\title{
EDITORIAL
}

\section{A VIEW FROM THE USA ON THE ALZHEIMER'S DISEASE INTERNATIONAL POSITION PAPER}

\author{
L.Z. RUBENSTEIN
}

Professor of Medicine, UCLA School of Medicine, VA Medical Center, Geriatric Research Education \& Clinical Center, 16111 Plummer Street, Sepulveda, CA 91343, USA; laurence.rubenstein@va.gov

The international position paper on the primary care physician and Alzheimer's disease (AD) appearing in this issue nicely lays out an ideal yet practical guideline for what should take place in primary care. It presents the rationale for early detection, accurate diagnosis and systematic care management of patients with AD in primary care settings. Early and accurate diagnosis is clearly vital in order to optimize care planning and long-term outcomes for AD patients and their families. Moreover, the primary care physician (PCP) is in the best situation to perform this detection, diagnosis, and care planning process.

In the United States, we have come a long way in the past 20-30 years in recognizing dementia within primary care settings and knowing how to help the patient and family. In previous years, the PCP would often simply label dementia patients as people with "organic brain syndrome," prescribe antipsychotic agents, and recommend nursing home placement. Things are better now. Most PCPs are familiar with AD as an entity, know how to diagnose it (or whom to call for help), and are aware of basic treatment options and where to refer for long-term management. Still, the typical PCP is still not performing up to the standards suggested in the position paper. First of all, there is still under-recognition of AD. By delaying the diagnosis, opportunities to improve the care process and disease trajectory are missed, with negative consequences (1-4). While there is certainly an understandable reluctance to label a person prematurely as having $\mathrm{AD}$, and thereby possibly initiate a cascade of deleterious perceptions and outcomes for an individual who is still functional, most evidence suggests that the greater benefit accrues from early diagnosis and care planning (1). Next, once AD is recognized, PCPs are often in a quandary as to how best manage the patient within a busy practice setting operating inside a healthcare system that fails to reimburse the PCP's time adequately for cognitive activities. Typically there is not ready access to a geriatrician, psychiatrist, neurologist or interdisciplinary team who can be called on for consultation and referral. As a result, PCPs often reach too rapidly to anti-cholinesterase inhibitors or antipsychotics, without first trying to optimize the symptoms or quality of life with behavioral techniques, teamwork or family education.
Yet there is hope on the horizon. Several specialty groups and national task forces have come out in favor of innovative care for $\mathrm{AD}$ and the important role of the $\operatorname{PCP}(1,6)$. A number of innovative care plans, collaborative care systems and specialized AD care programs have shown improved outcomes for $\operatorname{AD}$ patients $(2,5,7,8)$. While we are not yet able to dramatically change the long-term trajectory of $\mathrm{AD}$, we can improve quality of life, family satisfaction and other important intermediate outcomes. The present international position paper (9) is consistent with these US task force and specialty group reports, and its international consensus does much to furthering the cause of improved diagnosis and care for $\mathrm{AD}$ patients.

Financial disclosure: None of the authors had any financial interest or support for this paper.

\section{References}

1. Boustani M, Peterson B, Hanson L, et al. Screening for Dementia in Primary Care: A Summary of the Evidence for the U.S. Preventive Services Task Force. Ann Intern Med. 2003; 138: 927-937.

2. Callahan CM, Boustani MA, Unverzagt FW, et al. Effectiveness of collaborative care for older adults with Alzheimer disease in primary care: a randomized controlled trial. JAMA. 2006 295(18):2148-57.

3. Milne A, Culverwell A, Guss R, et al. Screening for dementia in primary care: a review of the use, efficacy and quality of measures. Int Psychogeriatr. 2008;20(5):911-26.

4. Valcour VG, Masaki KH, Curb JD, Blanchette PL. The detection of dementia in the primary care setting. Arch Intern Med. 2000; 160(19):2964-8.

5. Lai CK, Yeung JH, Mok V, Chi I. Special care units for dementia individuals with behavioural problems. Cochrane Database Syst Rev. 2009 Oct 7;(4):CD006470.

6. Small GW, Rabins PV, Barry PP Diagnosis and treatment of Alzheimer disease and related disorders. Consensus statement of the American Association for Geriatric Psychiatry, the Alzheimer's Association, and the American Geriatrics Society. JAMA. 1997 278(16):1363-71

7. Wenger NS, Roth CP, Shekelle PG, et al. A practice-based intervention to improve primary care for falls, urinary incontinence, and dementia. J Am Geriatr Soc. 2009;57(3):547-55.

8. Wolfs CA, Kessels A, Dirksen CD, et al. Integrated multidisciplinary diagnostic approach for dementia care: randomised controlled trial. Br J Psychiatry. 2008; 192 : 300-5.

9. Villars H, Oustric S, Andrieu S, Baeyens JP, Bernabei R, Brodaty H, Brummel-Smith K, Celafu C, Chappell N, Fitten J, Frisoni G, Froelich L, Guérin O, Gold G, Holmerova I, Iliffe S, Lukas A, Melis R, Morley JE, Nies H, Nourhashemi F, Petermans J, Ribera Casado J, Rubenstein L, Salva A, Sieber C, Sinclair A, Schindler R., Stephan E, Wong RY, Vellas B. J Nutr Health Aging. 2010; 14(2):110120 